\title{
4.8 The Influence of Anthropogenic Landscape Changes on Weather in South Florida
}

Roger A. Pielke Sr., Curtis Marshall, Robert. L. Walko, Louis T. Steyaert, Pier-Luigi Vidale, Glen E. Liston, Walter A. Lyons, Thomas N. Chase

\subsubsection{Motivation and Objectives}

Model simulations in two studies were used to assess the extent to which land-use change in south Florida may have affected local precipitation during the summer season. A more detailed discussion of this work appeared in Pielke et al. (1999) and Marshall et al. (2004). Previous studies in other geographic areas demonstrated that landscape patterns can generate local atmospheric circulations due to contrasting surface properties that can be as strong as a sea breeze caused by a land-water contrast (see Pielke 2001, for a review).

\subsubsection{Description of Study}

The Regional Atmospheric Modeling System (RAMS) Version 4.3 was used for the numerical simulations presented in this study (Marshall et al. 2004). All of the simulations were performed on a nested grid configuration with an outer grid of $42 \times 48$ points at a $40 \mathrm{~km}$ interval covering the southeast Atlantic and Gulf Coast states, southward to the latitude of the Yucatán Peninsula. An inner grid with $42 \times 50$ points at $10 \mathrm{~km}$ spacing was nested to cover central and south Florida and adjacent coastal waters. Both grids extended over 30 vertical levels, with the lowest level near $100 \mathrm{~m}$ above ground level. The vertical grid spacing was geometrically increased with height to a maximum of $1 \mathrm{~km}$ at the model top $(20 \mathrm{~km})$. Initial conditions and outer grid lateral boundary conditions were provided by the National Centers for Environmental Prediction-National Center for Atmospheric Research (NCEP-NCAR) global analysis dataset (Kalnay et al. 1996). During the integration of the simulations, the reanalysis data were updated every $6 \mathrm{~h}$ and nudged over the five outer grid points at each time step.

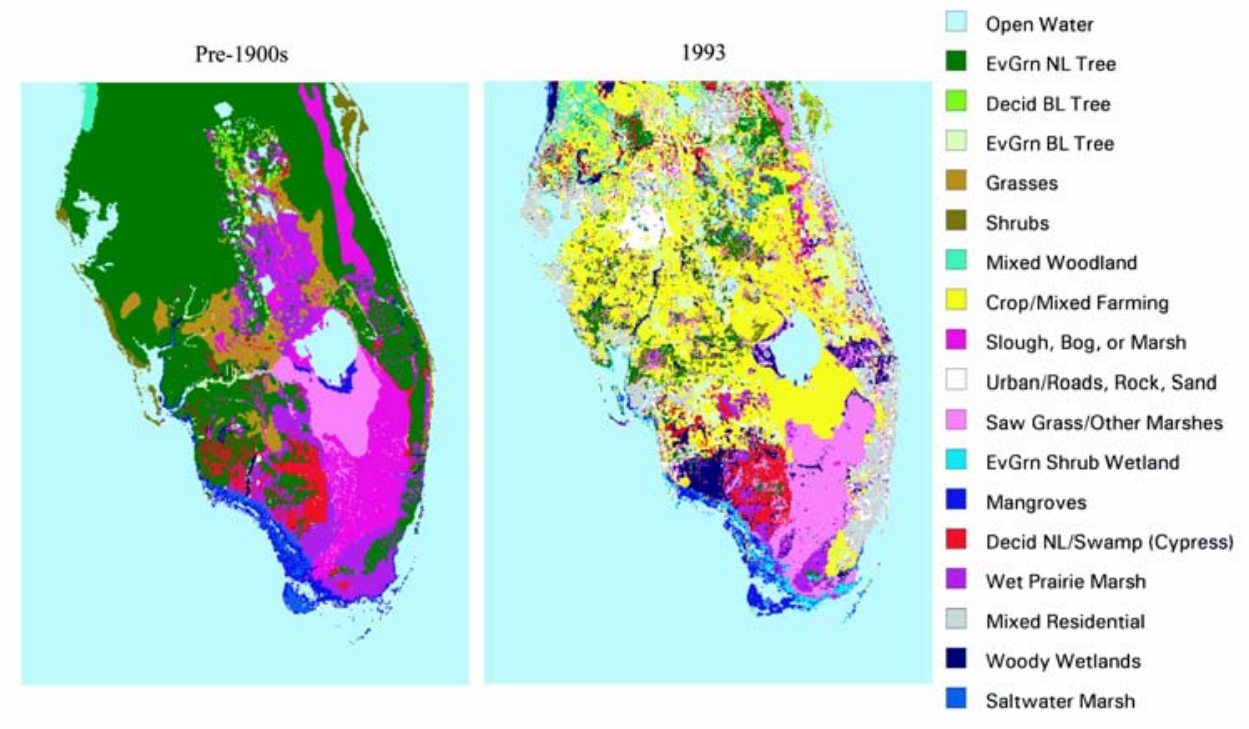

Fig.4.8-1: USGS land-cover data for (left) pre-1900 natural land cover and (right) 1993 land use (from Marshall et al. 2004). 


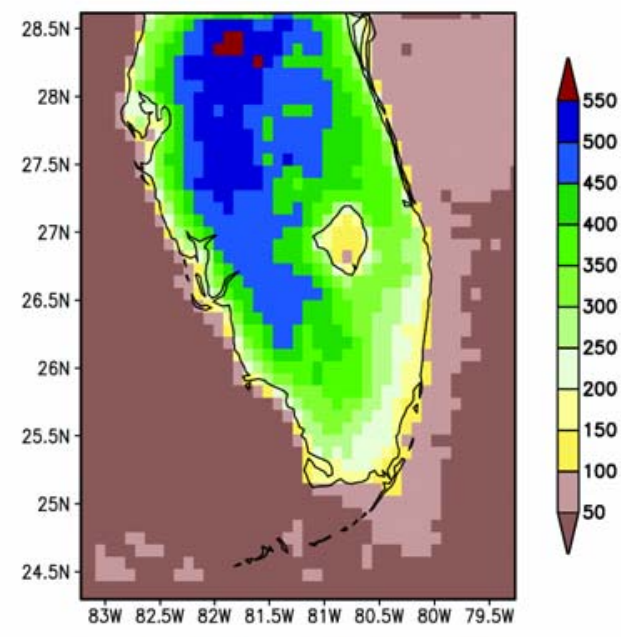

\subsubsection{Complexity of the Study}

The experiments differed solely in the definition of land-use category and initial soil moisture. The observed land-use change is illustrated in Fig. 4.8-1. The land-use change is prescribed (a one-way feedback to the atmosphere), with the biophysical effect of sensible and latent turbulent heat fluxes two-way interactive between the soil, vegetation and the atmosphere.

The representation of the surface heat energy and moisture budgets used the LEAF-2 scheme (Walko et al., 2000). LEAF-2 provides algorithms to partition incoming net radiation into sensible heat fluxes, physical evaporation and transpiration based on landscape type and more rapidly varying land-surface conditions such as soil moisture. Sea surface temperatures were obtained from the global climatological files at the National Center for Atmospheric Research (NCAR). The July and August average values are used.

\subsubsection{Results}

Fig. 4.8-2 shows the accumulated two-month deep cumulus precipitation for July-August 1973 using pre-1900 land cover and 1993 land use from the Marshall et al (2004) study. The difference between these two model simulations is shown in the bottom panel. The differences exceed $100 \mathrm{~mm}$ and more in places, along with an altered spatial pattern. The human-caused landscape change has apparently had a major effect on the hydrology of the region. The spatial pattern of the simulated rainfall for the 1973 model run is consistent with the climatological pattern of rainfall. The areaaveraged rainfall decrease is over $10 \%$. This reduction in rainfall reduces the amount of water

Fig. 4.8-2: Accumulated convective rainfall $(\mathrm{mm})$ from the model simulations of July-August 1973 with pre-1900 land cover (top), 1993 land use (middle), and the difference field for the two (bottom; 1993 ;minus pre-1900 case). From Marshall et al. 2004. 
that reaches the Everglades areas. The average maximum surface air temperature occurring for the entire period has increased in the model by about $2^{\circ} \mathrm{C}$ for many inland areas.

There are, unfortunately, only limited data available with which to evaluate temporal trends over south Florida, which makes comparison with the model results difficult. Fig. 4.8-3 shows regionally-averaged precipitation data during July and August for at least part of this past century. The model results indicate that if land-use change were the only factor influencing rainfall, we would expect a general decrease in rainfall over the interior, although there is considerable grid-point to grid-point variability near Lake Okeechobee and the coastlines. Some locations along the coast show a modest increase in rainfall.

The differences in precipitation in the model are due to the alteration in the spatial pattern of transpiration and physical evaporation due to the land-cover change. The reduction in this water flux to the atmosphere results in less precipitation in the interior of the peninsula from thunderstorms and a spatial displacement in the rainfall pattern.

Fig. 4.8-4 presents regionally-averaged maximum temperature trends. The observed increase in maximum averaged temperature for July and August is consistent with the model simulated warming in response to land-use change.

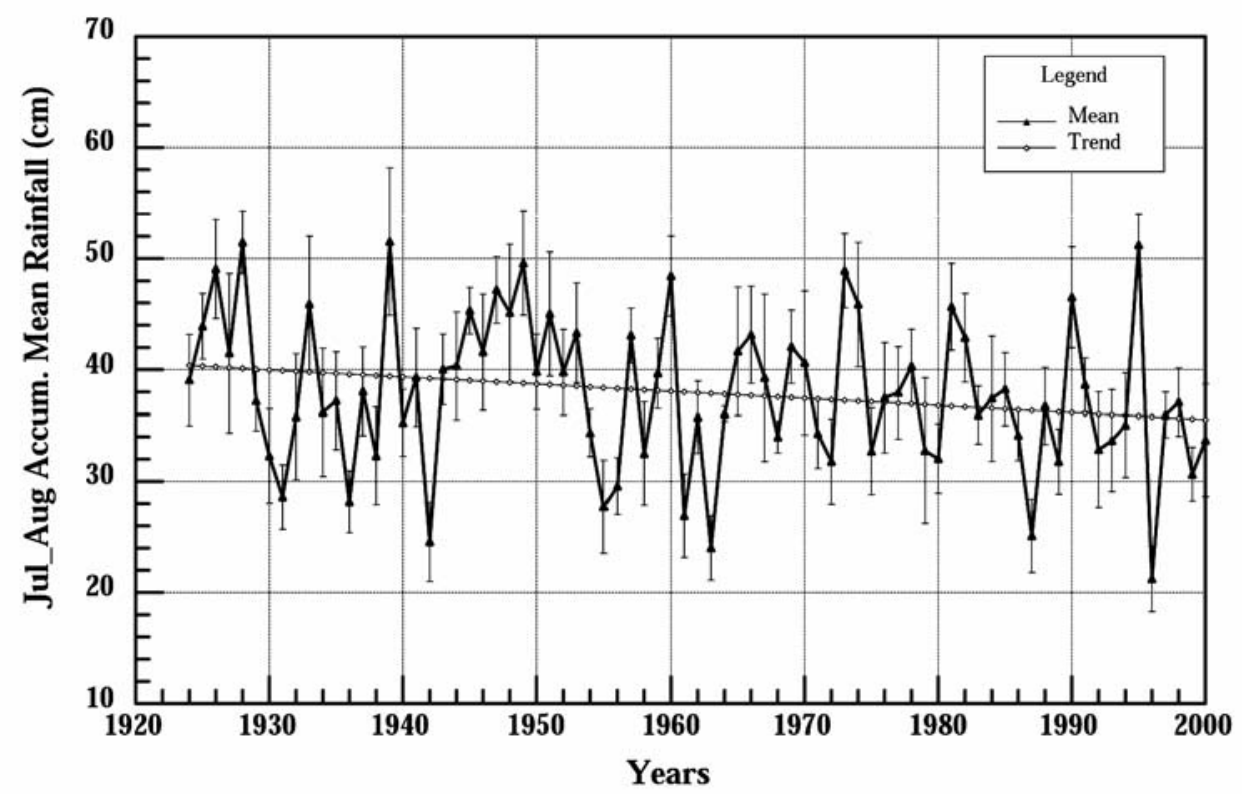

Fig. 4.8-3: Regional average time series of accumulated convective rainfall (cm) from 1924 to 2000, with corresponding trend based on linear regression of all July-August regional average amounts. The vertical bars overlain on the raw time series indicate the value of the standard error of the July-August regional mean (from Marshall et al. 2004). 


\subsubsection{Conclusions}

Over south Florida during the past 100 years, there has been a widespread conversion of natural vegetation to urban and agricultural land, and into grassy shrubland. These landscape changes are likely to have altered the local weather patterns, with average summer rainfalls for south Florida decreasing by $10 \%$ or more. This reduction in precipitation due to land-cover changes would be in addition to precipitation variability (which is also evident in Fig. 4.8-3) caused by year-to-year variability and long-term trends in synoptic weather features.

Along with the reduction in deep cumulus rainfall, the model indicated that surface temperatures should warm in response to the landscape conversion. A warming is observed in the regional averaged maximum temperatures. These results indicate that unless land-use change effects on weather are included in climate trend analyses, the reasons for climate change can be concluded erroneously. In addition, because of the permanent landscape changes in the regions around the Everglades, it will be impossible to restore the climate in this region to what it was prior to the landscape change, thereby making the restoration of the Everglades ecosystem even more difficult. Rainfall, for example, is likely to be permanently less in the absence of changes in larger-scale climate influences.

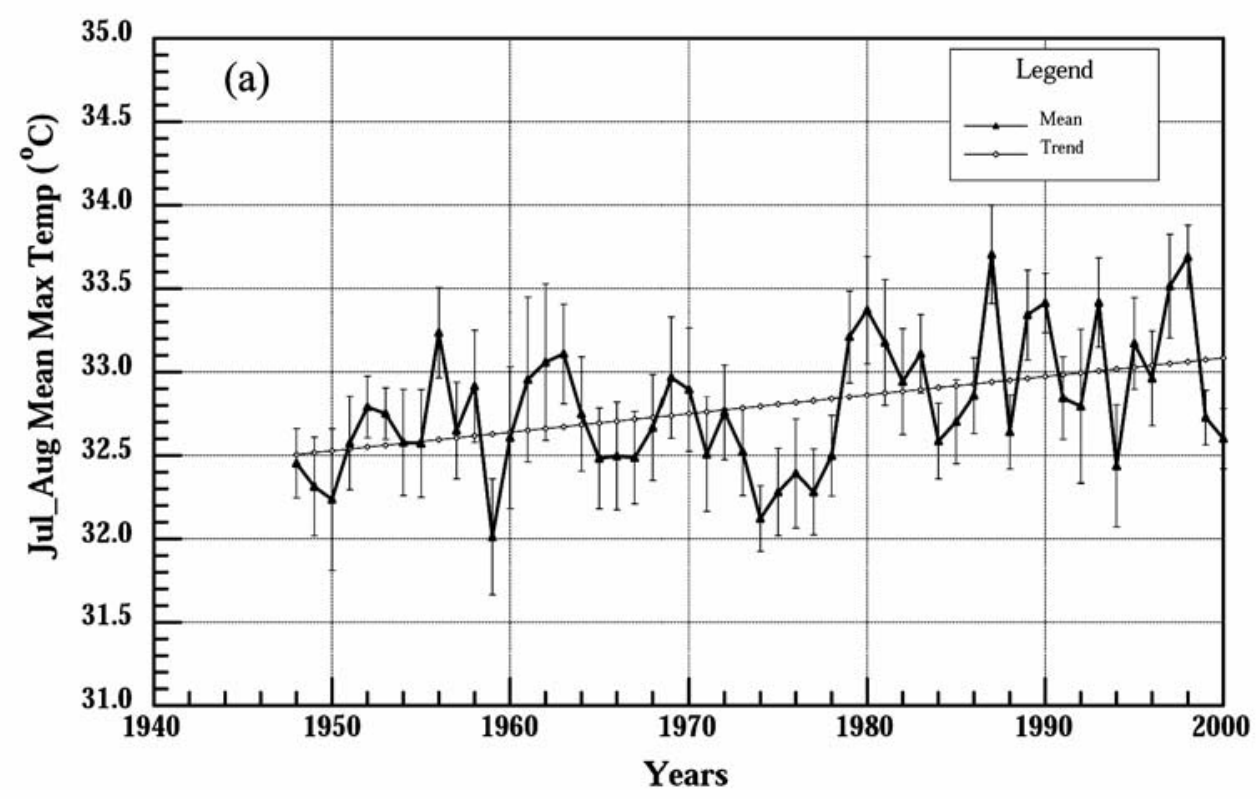

Fig. 4.8-4: Same as Fig. 4.8-3 except for daily maximum shelter-level temperature in degrees $C$.

\section{Acknowledgements}

Portions of this work was originally reported in Marshall et al. (2004). This research was supported by USGS Contract \#1434-CR-97-AG-00025, Task 7, and NASA Grant No. NAG511370. 


\subsubsection{References}

Kalnay, E. and coauthors, 1996: The NCEP/NCAR 40-year Reanalysis Project. Bull. Amer. Meteor. Soc., 77, 437-471.

Marshall, C.H. Jr., R.A. Pielke Sr., L.T. Steyaert, and D.A. Willard, 2004: The impact of anthropogenic land-cover change on the Florida Peninsula sea breezes and warm season sensible weather. Mon. Wea. Rev., 132, 28-52.

Pielke, R.A. Sr., 2001: Influence of the spatial distribution of vegetation and soils on the prediction of cumulus convective rainfall. Rev. Geophysics, 39, 2, 151-177.

Pielke, R.A., W.R. Cotton, R.L. Walko, C.J. Tremback, W.A. Lyons, L.D. Grasso, M.E. Nicholls, M.D. Moran, D.A. Wesley, T.J. Lee, and J.H. Copeland, 1992: A comprehensive meteorological modeling system -- RAMS. Meteor. Atmos. Phys., 49, 6991.

Pielke, R.A., R.L. Walko, L. Steyaert, P.L. Vidale, G.E. Liston, and W.A. Lyons, 1999: The influence of anthropogenic landscape changes on weather in south Florida. Mon. Wea. Rev., 127, 1663-1673.

Walko, R.L., L.E. Band, J. Baron, T.G.F. Kittel, R. Lammers, T.J. Lee, D.S. Ojima, R.A. Pielke, C. Taylor, C. Tague, C.J. Tremback, and P.L. Vidale, 2000: Coupled atmospherebiophysics-hydrology models for environmental modeling. J. Appl. Meteor., 39, 931-944. 